\title{
Esquecer Peirce? Dificuldades de uma teoria da comunicação que se apoia no modelo lógico e na religião. Parte II
}

Ciro Marcondes Filho

Resumo: No primeira parte deste ensaio, que comenta a semiótica peirceana, falou-se que Peirce é, antes de tudo, um lógico e um metafísico, não um teórico da comunicação. Apoiando-se na ideia de que todo real é racional, busca enquadrar em suas vacilantes trilogias todas as interpretações sob uma lei do signo e um imperativo do código. Seu rigor lógico-positivista não prevê espaço para objetos da percepção nem para o extralinguístico. Nesta segunda parte, comentam-se os limites do método diagramático, a tendência paradoxal de sua regressão infinita terminar na ideia e na metafísica religiosa. E, last but not least, fala-se do uso da semiótica para compromissos escusos com as novas formas de poder.

Palavras-chaves: semiótica; Peirce; método diagramático; logocentrismo; web 3.0

Abstract: Forget Peirce? Difficulties of a theory of communication underpinned by the logical model and by religion. Part II - In Part I of this essay, which deals with Peircean semiotics, we stated that Peirce is, above all, a logician and a metaphysician rather than a communication theorist. Based on the idea that everything real is rational, he seeks to fit all the interpretations into his faltering trilogies under a law of the Sign and an imperative of the Code. The rigor of his logical positivism does not provide space for objects of perception or for the extralinguistic. In this second part of the essay, we discuss the limits of the diagrammatic method, and the paradoxical tendency that Peirce's infinite regression has for ending in the Idea and in religious metaphysics. And last but not least, we discuss the use of semiotics in unscrupulous commitments to the new forms of power.

Keywords: semiotics; Peirce; diagrammatic method; logocentrism, web 3.0 


\section{Limites do método diagramático}

A proposição metodológica da semiótica peirceana realça o procedimento dedutivo em prejuízo da forma fenomenológica de exploração do acontecimento. Por isso, talvez, ele nem sequer considere a existência de um acontecimento comunicacional. Diz Peirce:

É função da inferência abdutiva associar o signo icônico, provindo do processamento de dados sensoriais, a uma imagem geral da memória, formando julgamentos de percepção, ou seja, tipos gerais de proposições. De outro modo, a instância abdutiva se processa na percepção, ou seja, na relação entre mente cognoscente e objeto investigado, num intervalo temporal, eximindo-se o autocontrole, pois a formação de uma hipótese independe da racionalidade dedutiva(PIERCE, C.P. 5.115).

Fica claro, mais adiante, "que a única Rationale dos métodos Abdutivo (enquanto método) e Indutivo é essencialmente Dedutiva ou Necessária" (ibidem, p. 5.146). Com efeito,

por raciocínio diagramático, pretendo dizer raciocínio que constrói um diagrama de acordo a um preceito expresso em termos gerais, dirige experiências nesse diagrama, anota os seus resultados, assegura-se de que qualquer experiência similar dirigida sobre qualquer diagrama construído de acordo com os mesmos preceitos deverá ter os mesmos resultados, e expressar isto em termos gerais (NEM 4:47-48, citado por Inácio, s/d, p. 2-3) .

Dessa maneira, apesar de considerar a indução, ela não passa de um primeiro estágio do processo cognitivo cuja efetivação vai acontecer na dedução. E isso é absolutamente coerente com seu olhar lógico sobre os signos e os dados da cultura, olhar esse que prima por se afastar do procedimento complexo, entendendo por este último o procedimento que associa o evento à rede de vinculações e determinações contextuais. Daí também sua simpatia pela representação diagramática da relação entre signo, objeto e interpretação, a ponto de confundir diagrama com o próprio ícone. Em algumas passagens, onde ambos os termos aparecem, Peirce revela que diagramas são tratados como ícones (FARIAS, 2008, p. 3). Em outras, faz-se a diferença entre ícone "original" e "ícone atualizado" (em diagrama). De qualquer forma as definições se sobrepõem:

Um diagrama [...] é descrito, em 'On quantity' (1895) como "imagem visual, seja ela composta por linhas, como uma figura geométrica, ou uma sequência de signos, como uma fórmula algébrica, ou de natureza mista, como um grafo (NEM 275,idem).

E o cognitivo cede espaço ao diagramático:

No caso específico das representações lógicas do raciocínio consciente e autodeliberado, as interferências cognitivas são evitadas para dar espaço às experimentações sobre diagramas, à medida que é possível, a partir de tais resultados, compreender e prever tanto a amplitude de um argumento, quanto de suas consequências (JORGE, 2002, p. 6-7). 
A consequência dessa opção será não somente a supressão do procedimento complexo mas também da temporalidade. É o que Ibri vaidizer:

Se considerarmos um diagrama como um ícone de relações evidenciadas à visão, ter-se-á diante dela, a presentidade de todos aqueles predicados relacionais. Ora, pensamos ser esta a ideia de tempo contida no conceito kantiano de esquema, em que, na realidade, o tempo é abolido para a intuição (IBRI, 1994, p. 128-129).

Ibri considera que a importância do tempo no diagrama é, na realidade, sua vital ausência. Conhecemos isso do modelo estruturalista, com a diferença que neste há uma estrutura inconsciente e ausente presidindo as relações sociais e as explicando. Já, aqui, o diagrama é eminentemente matemático, não supondo nada além do feixe de linhas e relações. É a partir do diagrama e só dele que, segundo Ibri, se pode ver o surgimento do inesperado:

"a presentidade nas ideias" torna-se a condição heurística do método, quer dizer, na
medida em que dispensa operações mnemônicas permite a contemplação livre de cons-
trições o que lhe dá a "idealidade criadora", a capacidade de descobrir novas relações
e permite ao diagrama "causar surpresas" (ibidem, p. 128-9).

O raciocínio diagramático, apoiado na representação visual, direta, analógica, usado como fonte de inferências, teria, na opinião dos semióticos peirceanos, inúmeras vantagens, como

a facilidade da localização dos problemas devido às especificações visuais; a menor necessidade de símbolos ou etiquetas, consequência precisamente do ponto anterior; ser mais fácil ao ser humano inferir visualmente em diagramas, demorando menos tempo do que em processos de fórmulas lógicas; por fim, o fato de as inferências estarem já presentes no diagrama: propriedades emergentes (INÁCIO, s/d, p. 3).

O que há, portanto, é uma opção epistemológica calcada na escolha do esquema visual facilitador em detrimento naturalmente de um modelo reflexivo. Também Vilém Flusser era de opinião que as pessoas deveriam começar a "filosofar por imagens", apostando na magia dos esquemas visuais (FLUSSER, 2003, p. 7-21). Para ele, a filosofia não foi sempre discursiva, havendo também uma filosofia matemática, a análise lógica e o neopositivismo. Ele acreditava que de algumas décadas para cá se estaria observando um novo desenvolvimento, o fato de as pessoas começarem a filosofar com imagens. Seriam as imagens numéricas que permitem visualizar formas platônicas de pensamento. Não obstante, o alcance desses instrumentos é específico e limitado. Florian Rötzer é alguém que o questiona, dizendo que filosofar com imagens significa fabricar cenas, mas não se pode fundamentar nem explicar nada, atos estes que foram até hoje normativos para a filosofia. A construção conceitual, abstrata e filosófica opera 
com planos outros, além da imagem. O esquema visual, diagramático, pode preencher algumas funções mas não é suficiente.

As críticas, contudo, não se limitam a isso. Há um mal-estar quando se lê Peirce afirmando que "o raciocínio diagramático é o único tipo realmente fértil de raciocínio" (PIERCE, CP 4.571), o que nos leva a supor certo dogmatismo do lógico. O mesmo acontece quando se lê que ele está em busca de "crenças estáveis" e de "observações indubitáveis":

Se a lógica pode ser definida como a ciência das leis que regulam o estabelecimento de crenças estáveis, a "lógica exata", enquanto doutrina das condições que fundamentam a lógica, deveria se basear em um tipo de pensamento cujas observações sejam indubitáveis (C.P. 3.429). Este é, de acordo com ele, o caso do pensamento ou raciocínio diagramático, também chamado de "icônico" ou "esquemático"(FARIAS, 2008, p. 6).

Ora, já vimos que toda essa infalibilidade, mesmo da matemática, caiu por terra quando Kurt Gödel demonstrou seu teorema da incompletude, que fala das proposições indecidíveis, aquelas que não podem ser provadas verdadeiras ou falsas em um dado sistema axiomático. Como sugere Ilário,

as distinções, da forma como estão postas, fazem um recorte demasiado formal para que se possa avançar para além da própria lógica, ou seja, para uma Ontologia no campo das Ciências Cognitivas(ILÁRIO, 2007, p. 59).

Peirce teria permanecido tão apegado aos seus próprios conectivos proposicionais e a uma representação simbólica ainda presa aos formalismos dos cânones da disciplina lógica, diz ele, que, na preocupação em demonstrar as tautologias da forma, deixou de levar ao limite uma topologia que aqui se busca demonstrar. Dessa forma,

Peirce não conseguiu plenamente transferir para o plano das suas representações toda a riqueza implícita na construção de conceitos a partir de outros conceitos, que nesse estudo denomino hiperdialética (ibidem, p. 59).

Certas categorias filosóficas, como o conceito de rosto em Levinas, a ideia de alteridade, o jogo entre o dito e o dizer, o espaço "entre" de Merleau-Ponty, a intuição, a diferença ontológica heideggeriana, seu conceito de "há", a noção de acontecimento, entre tantas outras, na melhor das hipóteses podem até ser objeto de uma esquematização diagramática provisória, mas isso permanece anos-luz aquém da densidade desses próprios conceitos.

A matemática opera por raciocínios lógicos e o diagrama é um instrumento adequado para uma grande quantidade de representações. Contudo, cabe perguntar se uma teoria da comunicação pode se contentar com esquemas de raciocínio e representações lógicas que deixam de lado outras dimensões, como a questão especulativa, a questão ética, 
a questão mesmo metafísica, no sentido que lhe dá Bergson, ou do empirismo transcendental, como o compreende Deleuze. Os diagramas podem ser modelos práticos mas insuficientes para mentes perseverantes e exigentes.

\section{Uma regressão infinita que, entretanto, ...se finda na ideia}

O procedimento peirceano opera com um conceito lógico de verdade, ou seja, a verdade em seu sistema só pode ser determinada por meios eminentemente lógicos. Nesse caso, o conceito de verdade não tem nada a ver com a correspondência entre uma inteligência que concebe, a saber, um espírito, e a realidade circundante, como pensava Tomás de Aquino. Sua verdade é de caráter linguístico (o que é verdadeiro não ou não verdadeiro não é a relação com o real mas a própria proposição) e, em outro plano, opera com a coerência: é verdadeira uma explicação se as proposições que a constituem formam um todo coerente, como no caso do diagrama. A isso, Peirce adiciona o componente pragmático: a asserção é verdadeira se ela permite agir eficazmente sobre o real, como já supunha James. A verdade, assim, nos explica Laugier, não é nem um dado, nem uma condição a priori do entendimento: ela é um resultado (LAUGIER, 1999, p. 750), que só acontecerá, contudo, no futuro,

já que o interpretante não é nada além de uma outra representação que recebe, abrindo o caminho, a chama da verdade; e, enquanto representação, tem, novamente, seu interpretante. Vê-se bem, é uma série infinita (ROBIN, 1967).

Esse conceito pragmático de verdade já havia sido refutado, no seu surgimento, pelo pensamento empirista, que não aceitava nenhuma verdade sem verificação, nem o fato de tomar o sucesso como regra do verdadeiro.

Outra maneira de ver a verdade é a de Espinosa, que, de certa forma, recebeu na contemporaneidade o apoio de Foucault. Para Espinosa, "a verdade se mostra pela sua clareza" - ou pela sua evidência - que é o que ele chamava de index sui. O critério espinosista da evidência faz coincidir a manifestação do verdadeiro com a obrigação que o indivíduo tem de conhecê-lo (CANDIOTTO, 2007). Pela evidência, não haveria outro regime de verdade a se agregar ao verdadeiro: "O próprio verdadeiro constitui seu regime, determina sua lei e me obriga" (FOUCAULT, 1980, apud Candiotto):

existe sempre e é preciso sempre supor uma certa afirmação que não é da ordem da lógica, da constatação ou da dedução; uma afirmação que não é da ordem do verdadeiro e do falso, mas que é muito mais uma espécie de engajamento, de profissão que consiste em dizer: é verdade, logo, eu me inclino (FOUCAULT, 2010, p. 71).

Essa verdade simples mas efetiva, que se impõe por si mesma, corresponde ao conceito de verdade da fenomenologia, assim como da nova teoria da comunicação, na forma 
da frase "a coisa opera em nós". Henri Duthu, a esse respeito, defende, como Bergson, a intuição como um procedimento altamente privilegiado para o conhecimento. Espinosa diz que "o verdadeiro é sua própria marca", que deve ser lido no sentido de surgir de um "contato direto do espírito com a coisa" (DUTHU, 2007), contato, portanto, de natureza fenomenológica, que exclui a intervenção de um sujeito, pois é a própria coisa que se entrega inteiramente a nós, ao nosso conhecimento (idem).

Trata-se de um procedimento totalmente diverso do caminho meramente racional, que é um caminho indireto, que neste caso não é tão valorizado. Não estando mais imediatamente presente ao nosso espírito nos tira a certeza de estar diante do verdadeiro, não sendo mais index sui.

A verdade, em Peirce, se realiza renovadamente. Contudo, o conceito peirceano de série infinita entra em contradição com a constituição de leis, característica do terceirismo. Peirce diz que

todo símbolo é uma coisa viva, num sentido muito restrito que não é uma figura de retórica. O corpo do símbolo muda lentamente, mas sua significação cresce inevitavelmente, incorporando novos elementos e rejeitando os antigos (5.594, p. 406).

Essa incorporação de novos elementos sugeriria uma eterna inconsistência, mais familiar a Heráclito do que a Platão, mas esse não é o caso de Peirce. Segundo ele, o universo tem a tendência de contrair leis, portanto, à cristalização progressiva. Se no passado não havia leis cósmicas, no futuro - acredita Peirce - não restaria mais nenhuma indeterminação, acaso, pois estaríamos no reino total da lei, seriam os "hábitos", que se constituem mesmo havendo ainda irregularidade e imprevisibilidade. É o mesmo que ele fala em 1891, quando diz que

a única teoria inteligível do universo é a do idealismo objetivo, segundo a qual a matéria é mente esgotada, na qual hábitos inveterados tornam-se leis físicas (PIERCE 6.25).

Ora, uma lei é uma regra obrigatória que exprime a natureza ideal de um ser ou de uma função, a norma à qual se deve conformar para se realizar (LALANDE, 1926, p.608). A base metafísica da definição testemunha mais uma vez a adesão peirceana ao idealismo (no caso, hegeliano), segundo o qual o espírito não é somente a "lei secreta da aparição das coisas, mas aquilo que deve aparecer por si mesmo" (CLÉMENT et ali, 2000, p. 191). Nesse ponto, Hegel distancia-se de Platão, para o qual as ideias "reinam eternamente numa transcendência imóvel", defendendo, contrariamente, que elas se revelam a si mesmas progressivamente e através de um percurso histórico necessário e determinado (idem). É um tipo de "regressão ao infinito" que, não obstante, na linguagem de Peirce, cristaliza-se na lei, no hábito. Contra a posição de Espinosa, Hegel, assim como Peirce, acredita que nada é verdadeiro por si mesmo, tudo deve ser investigado, verificado: a identidade não é jamais dada, mas sempre conquistada. Assim, 
o Espírito é aquilo que se realiza através da experiência de uma consciência: este último obstáculo, desde a sensação imediata do mundo até as ciências mais avançadas, um percurso pedagógico, um caminho iniciático, no curso dos quais é o próprio Espírito (a razão infinita que suplanta a simples consciência individual) que se conquista, que se realiza e se conhece (idem, p. 191-192).

\section{A metafísica religiosa de Peirce}

Segundo o agapismo peirceano, a doutrina do amor evolutivo, as pessoas adotam certas tendências de seu tempo por efeito de uma "atração imediata a uma ideia", momento esse em que se adivinha a natureza dessa mesma ideia antes mesmo que a mente racional a possua. Essa ocorrência é possível porque, conforme Peirce, há um contínuo entre a mente do cosmos e a mente humana, que ele chama de sinequismo.

O desenvolvimento agapista do pensamento é a adoção de certas tendências mentais, que não são totalmente desordenadas, como no tiquismo, nem totalmente cegas, como aquela que é produzida pela força das circunstâncias ou da lógica, como no anancastismo, mas que provém de uma atração imediata pela própria ideia, na qual a natureza é adivinhada antes que o espírito a possua, pelo poder de simpatia, isto é, em virtude da continuidade do espírito (6.307).

Peirce nos informa que essa "tendência mental" pode-se produzir de três formas: afetando toda uma comunidade, afetando uma pessoa isoladamente - mesmo que ela não compreenda essa ideia nem possa avaliar sua atração, a não ser pela simpatia das pessoas que lhe são próximas ou sob a influência de um pensamento que se propaga, como foi a conversão de São Paulo - e afetando um indivíduo pela atração que ela exerce sobre ele antes mesmo que ele a compreenda: "É o fenômeno que foi chamado, a justo título, de divinação [divination] do gênio, por ele se dever à continuidade que existe entre o espírito do homem e o Altíssimo"(6.307).

Não obstante, o amor evolucionário ou o agapismo não é um mero componente estimulante do saber, ele é parte obrigatória da prática científica. Ele é um dado da condição humana, diz Peirce, é o fato de o homem ter fé na evolução da ciência:

Peirce tem, assim, que forjar a ficção da atração agapista, ele tem que postulá-la como dado da condição humana, como condição dinâmica (psíquica) e epistemológica que permite ao pesquisador adicionar fé à evolução irreversível da ciência e à racionalidade do sentido comum crítico, que ele deve aí desdobrar (CARNOIS, 1983, p. 311).

Ora, diz Carnois, mas "a história e os acasos da pesquisa científica ensinam que o homem pode fazer parte dessa comunidade de pesquisadores sem tornar seu este tríplice 
engajamento de fé na racionalidade, esperança na acessibilidade de uma racionalidade última e de ágape, da qual Peirce torna condição necessária da prática científica" (idem).

Com efeito, a ética peirceana da pesquisa não apenas impõe essa postura místico-religiosa, como fecha as demais saídas da pesquisa:

Balizando a interrogação metacrítica pela questão epistemológica, pela lógica da pesquisa, se fecha a mesma pela descrição das condições éticas de qualquer uso científico dos signos, se fecha por uma ética agapista do conhecimento (CARNOIS, 1983, p. 311). [...] Ele bloqueia, assim, a abertura metacrítica da semiótica em relação à questão: 'O que é o homem?' Porque ele substitui aos resultados da própria pesquisa antropológica um tipo de pré-saber ético do homem: em sua teoria de engajamento agapista do pesquisador, ele determina o que é o homem que se engaja na pesquisa, o que ele se tornará necessariamente no fim da pesquisa e o que ele antecipa já, deste estado último, no seu uso presente dos signos. Aqui ele reconcilia bem ciência e religião no plano do senso comum mas ele não coloca a questão das condições semióticas do engajamento agapista à ciência (idem, p. 311-312).

Aí está. Bernard Carnois vê nitidamente que Peirce acopla ciência e religião,

fazendo dos a prioris prático-religiosos as condições necessárias e suficientes para a realização dos princípios reguladores da semiótica prática. Este gesto dogmático metateórico lhe é inspirado pelo seu otimismo religioso: ele repete aí, ao nível da fé no destino da ciência e na possibilidade de participar no espírito do Altíssimo, sua fé religiosa no destino do homem (idem, p. 312).

O engajamento agapista, para ele, funciona como uma espécie de "graça" que o pesquisador recebe. Com essa graça recebida, ele se põe a trabalhar para vê-la revelar-se nas abduções bem-sucedidas, exemplos notáveis da realização em forma de "graça icônica".

A aproximação da ciência e da religião foi vista no item anterior como realização do espírito absoluto: o verdadeiro se conquista através do atingimento progressivo daquilo que já se esperava. É uma antecipação, uma adivinhação, pois, no futuro, não há indeterminação, acaso, apenas o reino das leis. O que vai suceder é esse encontro feliz, a realização do espírito, a harmonia, enfim:

desejando assegurar esta finalidade nas próprias condições de possibilidade da pesquisa, Peirce se força a explicar o processo de abdução de forma romântica:postulando uma harmonia dinâmica preestabelecida entre o mundo, que é bom e agradável de conhecer, e aquele que se vai conhecer no final da pesquisa (CARNOIS, 1983, p. 313).

Teremos, aí, portanto, no final, o encontro feliz e bem-aventurado do bom, do belo e do verdadeiro. 
Esta produção é regulada harmonizando no objeto o bom (que é a única coisa que a atração agapista permite pesquisar), o belo (postulando para qualquer um uma atração subjetiva por um aspecto do fenômeno, que deve ser em seguida reconhecido por todos como constitutivo do fenômeno) e o verdadeiro (recorrendo-se à confirmação indutiva e controlando-se a compatibilidade do novo aspecto do fenômeno com aqueles que se conhecia antes) (ibidem, p. 313-314).

Para esse autor, a razão semiótica busca submeter percepção, ação e conhecimento à lei dos signos, ela procura uma adaptação infalível dos hábitos da ação aos hábitos de pensar o sentido dos signos. Essa adaptação é afirmada de forma categórica, mas sem se dizer como ela se produz (1983, p. 316). Trata-se aqui do grande equívoco peirceano de tentar resolver a questão kantiana de "o que eu posso saber?", reduzindo drasticamente o conhecimento possível ao "pensamento em signos", em que somente os signos podem identificar o que há de real no real.

O critério de validade de um conhecimento é sua eficácia - ou a capacidade de ele agir eficazmente sobre o real -, mas não "qualquer eficácia", pois, já disse Carnois, não basta que a experiência tornada possível pela hipótese científica corresponda a uma necessidade, é preciso que ela corresponda a uma necessidade racional. Além do pragmatismo de James, portanto, insere-se a precedência do racional. A verdade, confirma-se mais uma vez, é um resultado. Acontecerá apenas no futuro, quando se encontram as linhas do cosmos com as linhas do homem, numa perfeita ordem divina. O que desaparece é o demasiadamente humano daquilo que é o absolutamente incognoscível, a intuição, a introspecção.

\section{Implicações políticas da semiótica}

O professor italiano de semiótica Massimo Leone revela sua perplexidade diante dos perigos da semiótica na atualidade. Ele diz que os semioticistas, inclusive os "pais" da disciplina, transformaram os textos em "pretextos": o que importa, para eles, na análise, não é exatamente produzir um resultado hermenêutico, mas apenas demonstrar a validade de uma metodologia. Uma das razões principais pelas quais a semiótica desenvolveu-se principalmente como discurso metodológico sem objeto preciso, diz ele, é que os semióticos raramente foram encorajados a refletir sobre as motivações de suas escolhas pré-textuais (LEONE, 2010, p. 1). Os semióticos sempre se perguntam "como vou analisar este texto" e jamais "por que vou analisar este texto?", menos ainda, "para quem analisarei este texto?" (idem).

O ensaio de Leone, de caráter polêmico, surgiu de um mal-estar existencial do próprio autor diante da semiótica. Como tutor de jovens estudantes que preparavam suas dissertações na Universidade de Siena, deparou, certa feita, com uma jovem vestida totalmente de negro, com a cabeça raspada, portando uma folha de papel, buscando 
aconselhamento metodológico de sua pesquisa. No papel havia uma suástica negra sobre um fundo branco. Era 27 de janeiro, dia da memória judaica, comemorativa da entrada do Exército Vermelho em Auschwitz, em 27 de janeiro de 1945. Massimo Leone tomou o ato da jovem como uma provocação. Por alguns instantes ficou pasmo. Se tratasse a jovem como fazia com os demais, sugerir-lhe-ia literatura secundária sobre iconografia dos totalitarismos do século XX, sobre a estrutura plástica da cruz gamada, sobre as diferentes conotações desse símbolo em outras culturas, como a hindu etc. Ele manter-se-ia no campo restrito da semiótica, usando seus dispositivos teóricos, conceituais e analíticos para descrever o sentido da imagem. Não haveria problema algum. Assim como uma tela de Velásquez, uma foto de Cartier-Bresson, a suástica seria apenas um pretexto para testar a familiaridade dos estudantes com a metodologia semiótica.

O que incomodou Leone foi o fato de a semiótica poder ser ensinada e aprendida como um método que não leva a nenhuma reflexão sobre suas precondições epistêmicas. Para ele, a emergência da semiótica como "nova disciplina independente" coincidiria com a emergência da modernidade, particularmente com o início do que se chamou modernidade tardia ou pós-modernidade. Diferente da substituição do paradigma representado pela física quântica, que mudou o objeto de investigação, a alteração de paradigma realizada pela semiótica significou, conforme Leone, uma transformação do ângulo de investigação, ao proporcionar um método "total", capaz de descobrir interconexões secretas de todos os fenômenos e mesmo cobrir a distância entre ciências naturais e humanidades.

Excetuando-se em parte a semiótica de Lotman, que não é apenas semioticista, mas também filólogo e historiador, Leone sugere que Greimas e Peirce correspondem a esse modelo de tendência autorreferente, em que os interlocutores são outros semioticistas ou os estudantes de semiótica (LEONE, 2010, p. 11). Greimas, que contribuiu para o desenvolvimento do método estrutural na semiótica, raramente teria analisado um texto. Sua análise de Deux amis, de Maupassant, seria menos uma nova interpretação de seu objeto do que uma aplicação de seu método. No caso de Peirce, sabe-se que ele mesmo jamais empreendeu qualquer análise, apenas forneceu o instrumental lógico para que outros desenvolvessemsuas investigações. Mesmo Umberto Eco, utilizando-se do conceito peirceano de abdução, escreveu ensaios, mas "jamais interpretou um texto no interesse da interpretação" (idem, 2010, p. 7).

O depoimento de Leone, por interessante que seja, opera em um plano menos rigoroso que a discussão até aqui desenvolvida sobre Peirce. Uma coisa é Peirce como um lógico norte-americano voltado ao estudo dos signos ou sinais. Outra, é a utilização de seu aparato lógico para estudos de comunicação, especialmente análise das imagens (como objetos) e sua interpretação (curioso é que um dos campos mais férteis da semiótica, o secundismo, que fala da relação mútua entre observador e signo, de nossa reação diante do mundo, de os fatos externos resistirem à nossa vontade, ocupe um lugar muito pouco valorizado pelos semioticistas). Outra ainda são os usos da semiótica no atual quadro das 
disciplinas universitárias, que tratam dos efeitos políticos e ideológicos do trabalho do pesquisador e deslocam a temática para o campo eminentemente pragmático de seu saber.

Perguntando a seus alunos o motivo pelo qual optavam por trabalhar segundo o referencial teórico da semiótica, estes, totalmente desconhecedores do que foi no passado a "guerrilha semiótica", de Umberto Eco- que esclarecia as relações de poder dentro dos processos comunicacionais-, revelam que a posição política da semiótica inverteuse completamente: agora eles estudam semiótica porque ela é um dispositivo útil na comunicação comercial e particularmente na criação publicitária (LEONE, 2010, p. 10). É um fato denunciado por Barnard Carnois, de redução do uso lógico dos interpretantes à sua função cognitiva e, assim, restrição das possibilidades de transformação na prática da ciência (CARNOIS, 1983, p. 311).

Finalmente, mais um fator incomodante dessa inversão são efeitos outros, não diretamente observáveis no plano das profissões, mas na questão atual da computação. Em termos da semiótica, já não se trata do desenvolvimento do século XX, com Greimas, Eco, Lotman, "de aplicar o método descontroladamente a tudo"; hoje, a questão está no pensamento precedural do século XXI. Os textos a serem analisados poderão e deverão ser marcados e analisados de forma mecânica por dispositivos eletrônicos como a web 3.0.

Meu trabalho semiótico, independente de quão impecável ele possa ser do ponto de vista procedural, é cego. Eu utilizo o método semiótico degradando-me numa máquina computacional (LEONE, 2010, p. 10, grifo nosso).

É, contudo, no atual quadro do desenvolvimento das práticas em operação na internet que se deve ficar atento para usos políticos da semiótica com fins discutivelmente democráticos:

no novo pensamento procedural da semiótica do século 21, esta fantasia [a de analisar a forma pela qual se bloqueiam textos segundo quais dinâmicas culturais e enunciativas e, finalmente, ser capazes de fundar a legitimidade epistemológica da semiótica diante dos objetos] está sendo estendida do domínio metodológico ao analítico: se trabalharmos duramente esta fantasia - diz ela - nós poderemos elaborar não somente um procedimento para analisar textos de forma mecânica; nós poderemos igualmente elaborar um procedimento a fim de determinar, de forma mecânica, como marcar os textos que analisamos (LEONE, 2011, p. 9, grifo nosso).

A web 1.0 conectava informações. Suas máquinas de busca, seus portais de conteúdo, seus sites e suas databases operavam de forma sintática. A web 2.0 conecta pessoas. Trata-se de uma web social que faz expandirem-se os blogs, os e-mails, as conferências, as redes, os portais comunitários, os jogos multifuncionais. É a revolução do Facebook, do Twitter, do YouTube, mas também do Flickr, do BitTorrent. O que ocorre com a web 3.0 é mais radical. As máquinas agora querem falar umas com as outras, elas buscarão compreender o que os humanos desejam e aí é que entra a semiótica. 
Da web da informação está se passando à web do conhecimento. Trata-se, aqui, de uma nova geração de tecnologias que tem como objetivo representar a informação de maneira que os computadores sejam capazes de interpretá-las. As taxonomias (classificações de palavras) oferecem oportunidade para incluirsignificados na informação descrita na rede, permitindo que os computadores "raciocinem", quer dizer, realizem inferências. A web semântica conecta, portanto, "conhecimento": as informações conectadas têm significados compreensíveis e compartilháveis por pessoas e computadores. Há novos mecanismos de buscas, inferências, análise em bancos de dados. Ela dá maior "poder" aos computadores, que passam a "compreender" a informação disponível na internet.

Aqui se junta a compreensão das máquinas à semântica das redes. É a criação de sistemas coletivos de conhecimento. A web semântica representa a informação de forma explícita e com semântica para que os computadores possam compreendê-la e usá-la. Ao pesquisar algo, o resultado seria mais preciso, pois o usuário poderia fazer perguntas ao buscador e ele seria capaz de ajudá-lo de forma mais eficiente por entender melhor a necessidade do usuário, mesmo não sabendo o que este de fato deseja. Mas ela permanece atrelada a uma taxonomia: pelo Google, o usuário pesquisa um conteúdo a partir de uma referência, por exemplo, o nome de um cantor. Pela web 3.0, se ele não tem o nome, o sistema agrupa páginas com temas ligados a ele e fornecidos pelo usuário.

Temos, assim, agentes na web que sabem, aprendem e tomam decisões como se fossem pessoas. O sistema associa significados aos temas, realizando triagens, afunilamentos, reduções da ambiguidade. Na medida em que a máquina faz inferências, dá respostas e opera com sistemas de classificação ela marca os textos, os analisa e os impõe mecanicamente segundo regras semióticas. É o envolvimento procedural, que Leone chama de cego e que degrada o usuário numa máquina computacional. É também a forma como vê Foucault: uma verdade que estaria "ligada circularmente a sistemas de poder que a produzem e a sustentam, e a efeitos de poder que ela induz e que a reconduzem" (FOUCAULT, 1976-1988, p. 114). Cria-se um regime de verdade, segundo o qual os discursos não apenas funcionam como verdadeiros, mas também os mecanismos, as instâncias e os modos de distinguir entre o falso e o verdadeiro são definidos; os procedimentos e as técnicas para obtenção da verdade são produzidos; o estatuto daqueles que dirão a verdade é definido (idem). Como complementa Candiotto, "embora quaisquer práticas coercitivas reclamem sua verdade, não é dela que se trata, mas dos efeitos de poder que ela proporciona, tal como sua capacidade de justificar racionalmente distribuições, classificações, identificações".

Essa é a diferença entre um procedimento investigativo apoiado na semiótica peirceana e as formas de pesquisa em comunicação que veem a comunicação dentro de sua relação com o mundo, incomodada com os impactos que provoca e ciente de que não se trata de nada ingênuo. 
Ciro Marcondes Filho é professor titular da ECA-USP e autor da Nova teoria da comunicação, 7 vols., São Paulo, Paulus, 2010-2011.

ciromarcondesfilho@gmail.com

\section{Referências}

Observação sobre as citações originais de Peirce: Quando precedidas de MS e feitas entre colchetes, referem-se aos manuscritos inéditos, conforme a numeração feita por R. S. Robin, Annotated Catalogue of the Papers of Charles S. Peirce, Amherst, 1967; aquelas precedidas de C.P., feitas igualmente entre colchetes, são do Collected Papers of Charles Sanders Peirce, Vols. 1 a 6, editadas por C. Hartshorne e P. Weiss; volumes 7 e 8, editadas por A.W. Burks, Cambridge, 1931-1958. O primeiro algarismo é o número do volume e a numeração subseqüente, a da página. As obras citadas sob o título de "NEM", são especificadas abaixo. Já aquelas colocadas entre parêntesis são da edição brasileira desta mesma última obra, publicada pela Abril Cultural, São Paulo.

CANDIOTTO, Cesar. Verdade, confissão e desejo em Foucault. In: Revista Observaciones Filosoficas, 4, 2007.

CARNOIS, Bernard. Le sémiotique pragmatique de C. S. Peirce et ses limitations épistémologiques. In: Études philosophiques, 3, 1983.

CLEMENT, Cathérine et ali. La Philosophie de A à Z. Paris: Hatier, 2000.

DUTHU, Henri. Iniciation Philo. La connaissance rationnelle.Disponível em: <http:// www; initiationphilo.fr/articles.php?lng=fr\&pg=203>. Acesso em: 10 de maio de 2012.

ESPINOSA, Baruch. Ética. Trad. Tomaz Tadeu. 2 ed. Belo Horizonte: Autêntica, 2008 [1660].

FARIAS, Priscila Lena. O conceito de diagrama na semiótica de Charles S. Peirce. In: Tríades em Revista, ano 0, vol. 0, 2008. Disponível em: <http://usp.br.academia.edu/PriscilaFarias/Papers/557587/O_conceito_de_diagrama_na_semiotica_de_Charles_S._Peirce>. Acesso em:10 maio 2012.

FLUSSER, Vilém. Absolute. Freiburg: Orange-Press, 2003.

FOUCAULT, Michel. As palavras e as coisas. Uma arqueologia das ciências humanas. Lisboa: Portugália Editora, 1966.

. Du gouvernement des vivants . Cours au Collège de France, 1979-1980. Inédito. Arquivos do Imec, Paris, 1980a. Em português:

Do governo dos vivos. Curso no Collège de France, 1979-1980 (excertos). Trad./transc., notas e apresentação de Nildo Avelino. São Paulo/Rio de Janeiro: CCS/Achiamé, 1908b.

.Dits et écrits: 1976-1988.vol. 2. Paris: Gallimard, 2001.

GUINARD, Patrice. Critical Analysis of Peirce's Semiotics and an Ontological Justification of the Concept of the Impressional, 1993.Disponível em: <http://cura.free.fr/16peiren.html>. Acesso em: 10 maio 2012.

IBRI, Ivo Assad. Kósmos Poietikós -criação e descoberta na filosofia de Charles S.Peirce. (Tese de Doutorado). Universidade de São Paulo, inédita, 1994. 
ILÁRIO, Enídio. Contribuição para uma gramática especulativa: um novo enfoque em lógica diagramática no campo das ciências cognitivas. In: Ciência e Cognição, vol. II, p. 49-66, 2007.

INÁCIO, Luis M. Diagramas lógicos: a importância filosófica dos diagramas na lógica. Disponívem em: <http://independent.academia.edu/LuisInacio/ Papers/1296024/Diagramas_Logicos>. Acesso em: 10 maio 2012.

JORGE, Ana Maria Guimarães. Pensamento diagramático na semiótica dialógica de Charles S. Peirce. Intercom - Sociedade Brasileira de Estudos Interdisciplinares da Comunicação, XXV Congresso Brasileiro de Ciências da Comunicação - Salvador/BA - 1 a 5 set. 2002. In:LALANDE, André. Vocabulário técnico e crítico da filosofia. São Paulo: Martins Fontes, 1996 [1926].

LAUGIER, Sandra. Verbete "pragmatismo".In: Dictionnaire d'Histoire et Philosophie des Sciences. Coord. Dominique Lecourt. Paris: PUF, 1999.

LEONE, Massimo. Contre la sémiotique du prétexte, 2010. Disponível em: <http://unito.academia.edu/ MassimoLeone/Papers/1182902/2011_-_Contre_la_semiotique_du_pretexte>. Acesso em: 10 maio 2012.

Peirce. Questions Concerning Certain Dificulties Claimed for Man. In: Wiener, op. cit, 1868a.

Some Consequences of Four Incapacities. In: Wiener, op cit, 1868b.

. The Architecture of Theories. In: Wiener, P. P. (Org.). Charles Sanders Peirce, Selected Writings. New York: Dover, 1958.

[NEM]. New Elements of Mathematics by Charles S. Peirce.Ed. C. Eisele. The Hague: Mouton, 1976. [Obra citada como NEM, seguido pelo número do volume e número da página].

Escritos coligidos. In: PEIRCE;FREGE. Os pensadores. São Paulo: Abril, 1980.

ROBIN, Richard S. Annotated Catalogue of the Papers of Charles S. Peirce, Amherst 1967 - [Collected Papers, 1339]. Massachusetts: The University of Massachusetts Press, 1967

Artigo recebido em julho e aprovado em setembro de 2012. 